\title{
Models of Water Vapor Sorption by Hydlirophillic Polymers
}

\section{Advance Research in}

\section{Organic and Inorganic \\ Chemistry (AROIC)} Michael Ioelovich*

Volume 3 Issue 1, 2022

Article Information

Received date : February 03, 2022

Published date: February 14, 2022

*Corresponding author

Michael loelovich, Designer Energy,

Rehovot, 7670504, Israel

\section{Keywords}

Hydrophilic Polymers; Sorption of Water Vapors; Sorption Isotherms; Models; Universal Equation; Calculations.

\section{DOI:10.54026/AROIC/1005}

Distributed under Creative Commons CC-BY 4.0
Designer Energy, Rehovot, 7670504, Israel

\section{Abstract}

Various models and equations of water vapor sorption by hydrophilic polymers were considered. It was shown that these models often do not correspond to the sorption mechanism. These models can be mathematically adapted to the experimental isotherm regardless of the real sorption mechanism. Even when sorption occurs according to the same mechanism, various authors use different models and equations. This study is based on the volume absorption mechanism and the Van Krevelen method of group contributions. As a result, a universal physicochemical equation was proposed, which makes it possible to adequately describe the sorption isotherms of amorphous hydrophilic polymers knowing only the chemical formulas of repeating units of these polymers. To calculate the sorption isotherms for semicrystalline samples, it is necessary to use an additional parameter, namely the degree of amorphicity $(\mathrm{Y})$. The adequacy of the derived equation was verified for samples of cellulose and other natural polysaccharides, as well as for samples of synthetic hydrophilic polymers such as polyvinyl alcohol, polyamide-6, and polycaprolactone having various Y-values. The verification showed that the experimental isotherms are almost identical to the isotherms calculated by the universal equation.

\section{Introduction}

Hydrophilic polymers are a special class of polymers containing polar groups such as hydroxyl-, amino-, imine-, peptide-, ether-, ester-, and some others. These polymers can be natural (e.g, polysaccharides), artificial (e.g, partly substituted cellulose ethers and esters), and synthetic (e.g, polyamides and polyesters) $[1,2]$. Depending on whether the monomeric unit contains 5 or 6 carbon atoms, polysaccharides are classified also into C5-polysaccharides (C5P) and C6-polysaccharides (C6P). Despite the difference in structure and origin, all hydrophilic polymers have such a common specific feature as an affinity for water. Due to this feature, hydrophilic polymers can sorb water vapor, swell in water, and form gels, while some of them can dissolve in water [3]. Special studies have been devoted to disclosing the sorption mechanism of Water Vapor (WV) by hydrophilic polymers. Various sorption models have been proposed, such as the Langmuir model of monomolecular surface adsorption [4,5], BET, BAG, and GDW models of multimolecular surface adsorption [5-11], as well as models of Henry, Flory-Huggins, and Hailwood-Horrobin of water dissolution in polymers [6, 11-13]. In addition, also empirical models were used to describe the sorption isotherms [5]. Along with simplified models, mixed models have been developed that combine various sorption models such as surface adsorption, dissolution, clustering, capillary condensation of water molecules, etc. [11, 14-16]. There are many facts for a volume absorption mechanism interaction of water molecules with hydrophilic polymers. As known, the process of WV sorption by these polymers is accompanied by such phenomena as a swelling and partial dissolving of water-soluble polymers [17], a decrease of the glass transition temperature and even melting point, recrystallization of amorphized polymers, etc. [18-20]; in addition, when these polysaccharides are wetted, a significant amount of thermal energy is released $[17,21,22]$. All these phenomena are obvious evidence of the absorption mechanism of the interaction of water molecules with hydrophilic polymers. Therefore, it makes no sense to use surface adsorption models, such as the Langmuir, BET, BAG, and others, to describe the sorption of WV by volume-absorbing hydrophilic polymers. Regarding the Henry and Flory-Huggins models, it should be noted that these theoretical models were developed for ideal binary systems, to which the hydrophilic polymer-water system does not belong. The Hailwood-Horrobin model postulated the dissolution of VW in the internal structure of hydrophilic polymers during the sorption process with the formation of monohydrates and polyhydrates $[6,11-$ 13]. However, this hypothesis is doubtful since polymers cannot form chemical compounds with water such as monohydrates. It has also not been proven that polyhydrates are actually formed. The parameters of Hailwood-Horrobin's equation are selected in such a way as to achieve the best agreement with the experimental isotherm. This assists to adapt the model to the experiment but does not provide arguments about the real sorption mechanism.

According to the mixed model of Park, the sorption of WV by hydrophilic polymers is a complex process combining monomolecular adsorption at the initial stage, dissolution of water vapor in the biopolymers at the middle stage, and clustering at the last stage [14]. However, as was mentioned above it makes no sense to use the Langmuir model of monomolecular surface adsorption to describe the sorption of WV by absorbing polymers. On the other hand, the linear dissolution process of WV in the hydrophilic polymers following Henry's law is also unlikely, since this law is observed only for ideal solutions of low molecular substances. In addition, the clustering, i.e, multimolecular adsorption of water molecules in hydrophilic polymers has not been detected. Moreover, to describe each isotherm, the Park model requires the determination of five parameters [15]. If it is necessary to describe the isotherm of WV for another polymer sample, then the new five parameters must be recalculated. In fact, Park's model is mathematically adapted to the experimental isotherm without proof of the sorption mechanism. The same problem arises for a mixed model comprising the monomolecular surface adsorption of the Langmuir type and the Flory-Huggins dissolution process, which requires the use of three parameters at least to describe the experimental isotherm [16]. Thus, the analysis of the known sorption models revealed three main shortcomings. The first shortcoming is that these models often do not correspond to the real sorption mechanism. The second shortcoming is that the calculation of each isotherm in these models needs to be preliminarily found from three to five empirical parameters to achieve the best fit between the calculated and experimental isotherms. The third shortcoming is the lack of a universal calculating equation of the isotherms; even when sorption occurs according to the same mechanism, various authors use different models and equations. It should also be noted that any physicochemical model is needed only if it adequately describes not only the shape of the isotherm but also the sorption mechanism. However, if a model is limited only to the description of the isotherm shape, then such a physicochemical model is not necessary. For this aim, it is enough to involve a mathematical model, using, for example, a well-known polynomial function. Taking into account the foregoing, the main purpose of this study was to develop a universal physicochemical model and an equation that would adequately describe the absorption of water vapor by hydrophilic polymers of various origins in a wide range of relative vapor pressure, knowing only the chemical formulas of the monomer units of these polymers. 


\section{Materials and Methods}

Materials

The following samples of hydrophilic polymers were investigated, such as pure chemical-grade fibers of Cotton Cellulose (CC), Rayon Cellulose Fibers (RF), Powder Of Potato Starch (ST), Powder Of Birch Xylan (XL), Purified Powder Of Chitin (CT) of crab shells, Powdered Polyvinyl Alcohol (PV), Fibers of Polyamide-6 (PA) and Polycaprolactone (PC).

\section{Enthalpy of wetting}

The enthalpy of wetting of hydrophilic polymers was studied at $298 \mathrm{~K}$ by the method of precise microcalorimetry using a TAM III calorimeter [22]. The samples were preliminarily dried at $400 \mathrm{~K}$ in a vacuum chamber to constant weight. Three of the same samples were tested to calculate an average enthalpy value and standard deviation that was in the range $\pm 0.02 \mathrm{~J} / \mathrm{g}$. Using enthalpy value obtained fo semicrystalline sample $\left(\Delta_{\mathrm{w}} \mathrm{H}_{\mathrm{s}}\right)$, the degree of amorphicity $(\mathrm{Y})$ of various hydrophilic polymers was calculated, as follows:

$$
\mathrm{Y}=\Delta_{\mathrm{w}} \mathrm{H}_{\mathrm{s}} / \Delta_{\mathrm{w}} \mathrm{H}_{\mathrm{a}}(1)
$$

where $\Delta \mathrm{wHa}$ is wetting enthalpy of amorphous domains of a semicrystalline sample or completely amorphous hydrophilic polymer.

The obtained Y-values are presented in (Table 1).

Table 1: The amorphicity degree of studied samples of hydrophilic polymers

\begin{tabular}{|l|l|l|l|}
\hline Sample & $-\Delta_{\mathbf{w}} \mathbf{H}_{\mathbf{s}}, \mathbf{k J} / \mathbf{k g}$ & $-\boldsymbol{\Delta}_{\mathbf{w}} \mathbf{H}_{\mathbf{a}}, \mathbf{k J} / \mathbf{k g}$ & $\mathbf{Y}$ \\
\hline CC & 50 & 168 & 0.30 \\
\hline RF & 108 & 168 & 0.64 \\
\hline ST & 121 & 168 & 0.72 \\
\hline CT & 43 & 134 & 0.32 \\
\hline XL & 106 & 137 & 0.77 \\
\hline PV & 102 & 197 & 0.52 \\
\hline PA & 31 & 77 & 0.40 \\
\hline PC & 5 & 13 & 0.38 \\
\hline
\end{tabular}

Sorption of water vapor

The sorption experiments were carried out at $298 \mathrm{~K}$ on a vacuum Mac-Ben apparatus having helical spring quartz scales. Before starting the experiments, the samples were dried at $400 \mathrm{~K}$ up to constant weight and additionally degassed under vacuum in the sorption device. Three of the same samples were tested to calculate an average sorption value and standard deviation that was in the range $\pm 0.002 \mathrm{~g} / \mathrm{g}$.

\section{Results and Discussion}

Theory of water vapor sorption by hydrophilic polymers

The sorption process can be described using the fundamental Gibbs-Duhem equation for thermodynamic equilibrium in a binary system [23]

$$
\mathrm{N}_{1} \Delta \mu_{1}+\mathrm{N}_{2} \Delta \mu_{2}=\mathrm{S} \Delta \mathrm{T}+\mathrm{V} \Delta \mathrm{P}(2)
$$

where N1 and N2 are molar parts of the components in the binary system; $\Delta \mu$ and $\Delta \mu_{2}$ are specific thermodynamic potentials of the components; $\mathrm{S}$ is enthalpy; $\mathrm{V}$ is volume; $\mathrm{T}$ is temperature, and $\mathrm{P}$ is pressure.

For a binary system containing polar groups of amorphous hydrophilic polymer (p) and absorbed water $(w)$ under isothermal conditions $(\Delta T=0)$, this equation will be:

$$
\mathrm{N}_{\mathrm{w}} \Delta \mu_{\mathrm{w}}+\mathrm{N}_{\mathrm{p}} \Delta \mu_{\mathrm{p}}=\mathrm{V} \Delta \mathrm{P}(3)
$$

The hydrophilic polymer sorbent has many polar groups serving as sorption centers. When Water Vapor (WV) having pressure P is fed into a closed reservoir containing the polymer sorbent, a dynamic process begins until an equilibrium state is established. As a result, one part of the polar groups, $\Theta$, becomes occupied by wate molecules, while another part of the groups, $1-\Theta_{i}$, remains vacant. In addition, $\Theta_{i}$ is directly proportional to the molar fraction of sorbed water molecules: $\Theta_{\mathrm{i}}=\mathrm{n} \mathrm{a}_{\mathrm{i}}$. At the equilibrium state $\triangle P=0$. Thus, applying of the Gibbs-Duhem thermodynamics to the absorption process of $\mathrm{WV}$ gives the following equation:

$$
\Theta_{\mathrm{i}} \Delta \mu_{\mathrm{w}}+\left(1-\Theta_{\mathrm{i}}\right) \Delta \mu_{\mathrm{p}}=0(4)
$$

where $\Delta \mu_{\mathrm{p}}=$ const $=\mathrm{g}$, because the thermodynamic state of vacant polar groups of the polymer sorbent is constant; $\Delta \mu_{\mathrm{w}}=\mathrm{RT} \ln \varphi$ is the specific potential of the water molecules absorbed by polar groups at a relative vapor pressure, $\varphi=P / P_{0}$. As a result, the following equation can be obtained:

$$
\Theta_{\mathrm{i}}^{-1}=1-(\mathrm{RT} / \mathrm{g}) \ln \varphi(5)
$$

Under isothermal conditions $\mathrm{RT} / \mathrm{g}=$ const $=\mathrm{C}_{\mathrm{i}}$, and

$$
\Theta_{\mathrm{i}}^{-1}=1-\mathrm{C}_{\mathrm{i}} \ln \varphi(6)
$$

Since $\Theta_{\mathrm{i}}=\mathrm{n} \mathrm{a}_{\mathrm{i}}$, and the maximum $\Theta_{\mathrm{m}}=1=\mathrm{n} \mathrm{a}_{\mathrm{o}, \mathrm{i}}$, then $\Theta_{\mathrm{i}}=\mathrm{a}_{\mathrm{i}} / \mathrm{a}_{\mathrm{o}, \mathrm{i}}$, and the sorption equation will be the following:

$$
\begin{aligned}
& \mathrm{a}_{\mathrm{i}}^{-1}=\mathrm{a}_{\mathrm{o}, \mathrm{i}}^{-1}-\left(\mathrm{C}_{\mathrm{i}} / \mathrm{a}_{\mathrm{o}, \mathrm{i}}\right) \ln \varphi(7) \\
& \text { or } \mathrm{a}_{\mathrm{i}}=\mathrm{a}_{\mathrm{o}, \mathrm{i}}\left(1-\mathrm{C}_{\mathrm{i}} \ln \varphi\right)-^{-1}(8)
\end{aligned}
$$

where $\mathrm{a}_{\mathrm{i}}$ and $\mathrm{a}_{\mathrm{o}, \mathrm{i}}$ are the number of moles of water molecules sorbed by one mole of the polar group in the amorphous polymer at a certain relative vapor pressure, $\varphi$, and at $\varphi=1$, respectively.

Thus, relative sorption, $\Theta_{i}=a_{i} / a_{o j}$, under isothermal conditions depends only on the value of coefficient C. For example, if $\mathrm{T}=298 \mathrm{~K}$ and $\mathrm{C}=2$, then the isotherm will be S-shaped, while if $\mathrm{C}_{\mathrm{i}}=10$, then the Flory-Huggins type sorption isotherm can be obtained (Figure 1).

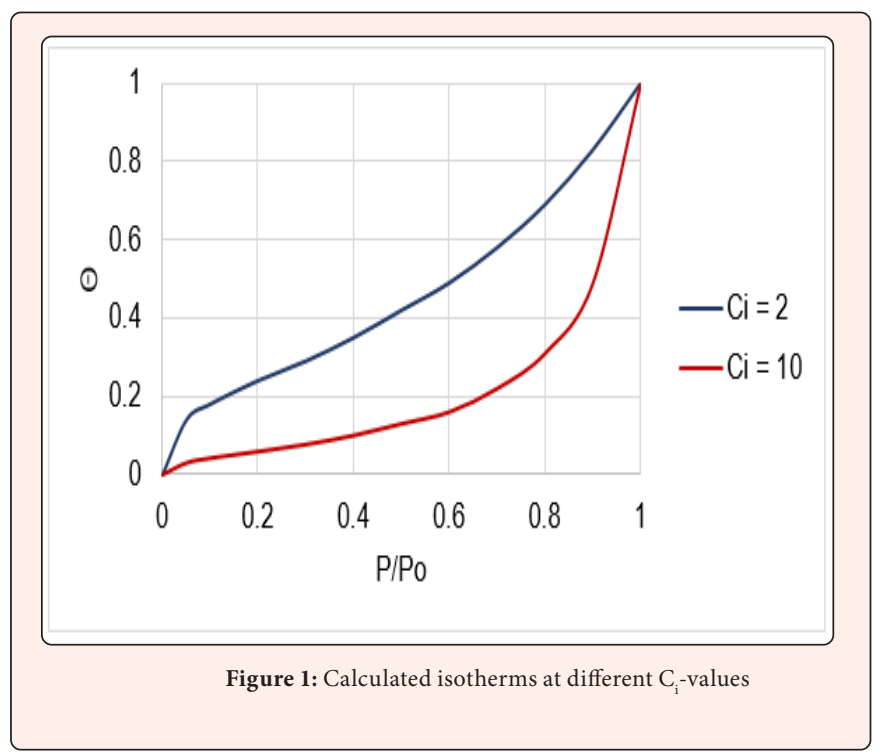

To find the parameters $\mathrm{a}_{\text {, }}$, and $\mathrm{C}_{\mathrm{i}}$ for different types of polar groups, the Van Krevelen table was used, showing the contributions of the polar groups of amorphous polymers to the absorption of water molecules at several $\varphi$ values and temperature 298 $\mathrm{K}$ [24]. For this purpose, a linear graph was plotted for each polar group in coordinates of eq. (7). As an example, Figure 2 shows a linear plot for the absorption process of WV by the hydroxyl group of an amorphous hydrophilic polymer.

Extrapolation of the linear plot $\mathrm{a}_{\mathrm{i}}{ }^{-1}=\mathrm{F}(-\ln \varphi)$ to $\ln \varphi=0$ gives the value $\mathrm{a}_{\mathrm{o}, \mathrm{i}}{ }^{-1}$, from which the maximum absorption value, $a_{\text {, }}$, for the group can be found. In addition, the slope coefficient $(\mathrm{k})$ of the plot can be also determined and coefficient $\mathrm{C}_{\mathrm{i}}=\mathrm{k} \mathrm{a}_{\mathrm{o}, \mathrm{i}}$ was calculated. 


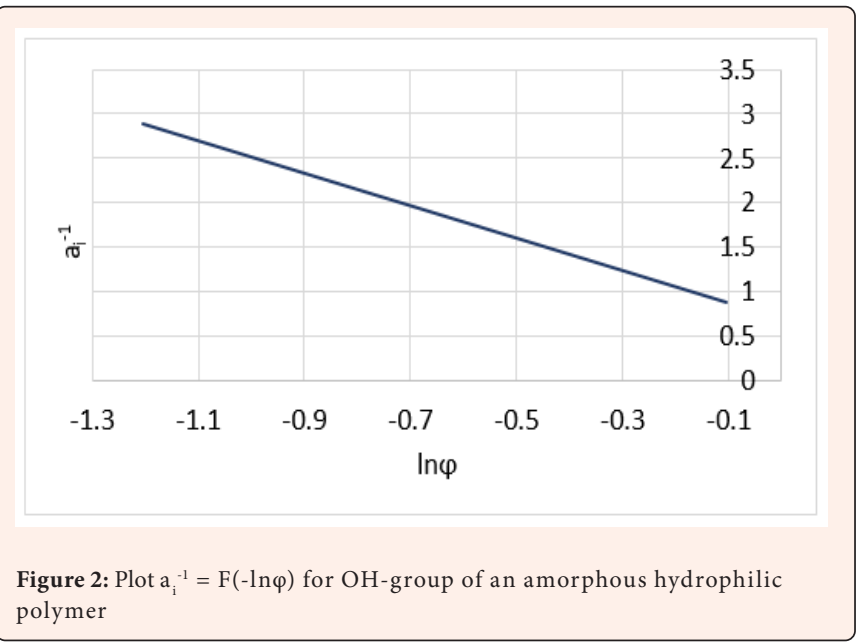

The parameters of $\mathrm{a}_{2, \mathrm{i}}$ and $\mathrm{C}_{\mathrm{i}}$ calculated for various polar groups of amorphous hydrophilic polymers or amorphous domains (AD) of the semicrystalline polymers are shown in (Table 2).

Table 2: Parameters of eq. (7) and (8)

\begin{tabular}{|l|l|l|l|}
\hline Polar groups & $\mathbf{p}_{\mathbf{i}}$ & $\mathbf{a}_{\mathrm{o}^{\prime}{ }^{\prime},} \mathrm{mol} / \mathrm{mol}$ & $\mathbf{C}_{\mathbf{i}}$ \\
\hline$-\mathrm{OH},=\mathrm{NH},-\mathrm{NH}_{2},-\mathrm{NHCO}-$ & 1.00 & 1.44 & 2.6 \\
\hline$-\mathrm{COOH}$ & 0.91 & 1.31 & 5 \\
\hline$-\mathrm{C}=\mathrm{O}$ & 0.21 & 0.30 & 6 \\
\hline$-\mathrm{COO}-$ & 0.17 & 0.24 & 7 \\
\hline$-\mathrm{O}-$ & 0.08 & 0.12 & 16 \\
\hline
\end{tabular}

$\mathbf{p}_{\mathrm{i}}$ is a relative sorption ability of the polar group

Calculation of sorption isotherms for amorphous hydrophilic polymers

Parameters of Eq. (7) and (8) allow calculation of the sorption values $\left(\mathrm{A}_{\mathrm{a}}, \mathrm{mol} / \mathrm{mol}\right)$ of $\mathrm{WV}$ for amorphous hydrophilic polymers or $\mathrm{AD}$ of the semicrystalline polymers at various $\varphi$, knowing only the chemical formulas of the repeating unit of these polymers including the type and number $\left(\mathrm{n}_{\mathrm{i}}\right)$ of polar groups, as follows:

$$
\mathrm{A}_{\mathrm{a}}=\sum \mathrm{n}_{\mathrm{i}} \mathrm{a}_{\mathrm{i}}=\sum \mathrm{n}_{\mathrm{i}} \mathrm{a}_{\mathrm{o}, \mathrm{i}}\left(1-\mathrm{C}_{\mathrm{i}} \ln \varphi\right)^{-1}(9)
$$

Moreover, the maximum amount of water molecules, $\mathrm{A}_{\mathrm{a}, \mathrm{o}}=\sum \mathrm{n}_{\mathrm{i}} \mathrm{a}_{\mathrm{o}, \mathrm{i}}$, absorbed by AD of polymers at $\varphi=1$, can be also calculated (Table 3 ).

Table 3: Maximum amount of water $\left(\mathrm{A}_{\mathrm{a}, \mathrm{o}} \mathrm{mol} / \mathrm{mol}\right)$ absorbed by $\mathrm{AD}$ of various polymers

\begin{tabular}{|c|c|c|c|c|}
\hline Polymer & Formula & MU & $A_{a, o}$ & $\mathrm{C}_{\mathrm{p}}$ \\
\hline C5P (Xylan) & $\mathrm{C}_{5} \mathrm{H}_{6} \mathrm{O}_{2}(\mathrm{OH})_{2}$ & 132 & 3.12 & 1.64 \\
\hline C6P (Cellulose and Starch) & $\mathrm{C}_{6} \mathrm{H}_{7} \mathrm{O}_{2}(\mathrm{OH})_{3}$ & 162 & 4.56 & 1.95 \\
\hline Chitin (CT) & $\mathrm{C}_{6} \mathrm{H}_{7} \mathrm{O}_{2}(\mathrm{OH})_{2}(\mathrm{NHCO}) \mathrm{CH}_{3}$ & 203 & 4.56 & 1.55 \\
\hline Polyvinyl alcohol (PV) & $\mathrm{CH}_{2} \mathrm{CHOH}$ & 44 & 1.44 & 2.27 \\
\hline Polyamide (PA) & $\left(\mathrm{CH}_{2}\right)_{5} \mathrm{NHCO}$ & 113 & 1.44 & 0.88 \\
\hline Polycaprolactone (PC) & $\left(\mathrm{CH}_{2}\right)_{5} \mathrm{COO}$ & 114 & 0.24 & 0.07 \\
\hline
\end{tabular}

$C_{p}=100 \sum n_{i} p_{i} / M U$ is the percentage concentration of polar groups in the mass of the repeating unit

The sorption values $\left(\mathrm{S}_{\mathrm{a}}\right)$ at various $\varphi$ for $\mathrm{AD}$ of the hydrophilic polymer expressed in $\mathrm{gH}_{2} \mathrm{O} / \mathrm{g}$ sorbent can be calculated, as follows:

$$
\mathrm{S}_{\mathrm{a}}(\mathrm{g} / \mathrm{g})=(\mathrm{MW} / \mathrm{MU}) \sum \mathrm{n}_{\mathrm{i}} \mathrm{a}_{\mathrm{o}, \mathrm{i}}\left(1-\mathrm{C}_{\mathrm{i}} \ln \varphi\right)^{-1}(10)
$$

where $\mathrm{MW}=18$ is the molecular mass of the water molecule.

Using the eq.(10), sorption isotherms for AD of various hydrophilic polymers can be calculated (Figures $3 \& 4$ ).

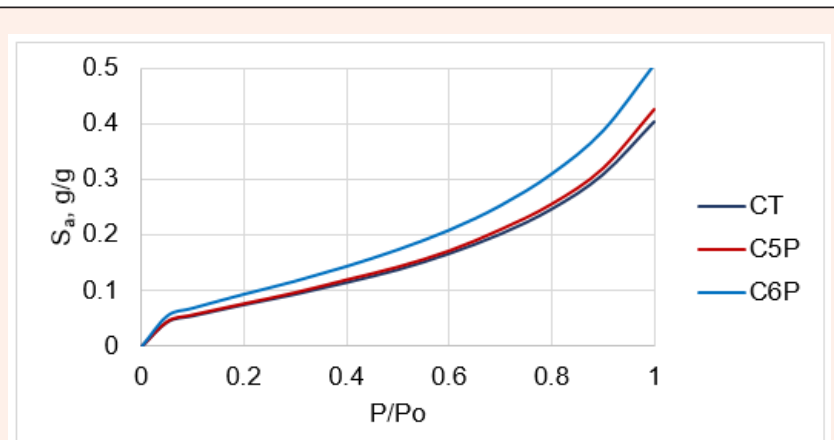

Figure 3: Calculated sorption isotherms of $\mathrm{WV}$ by $\mathrm{AD}$ of natural hydrophilic polymers

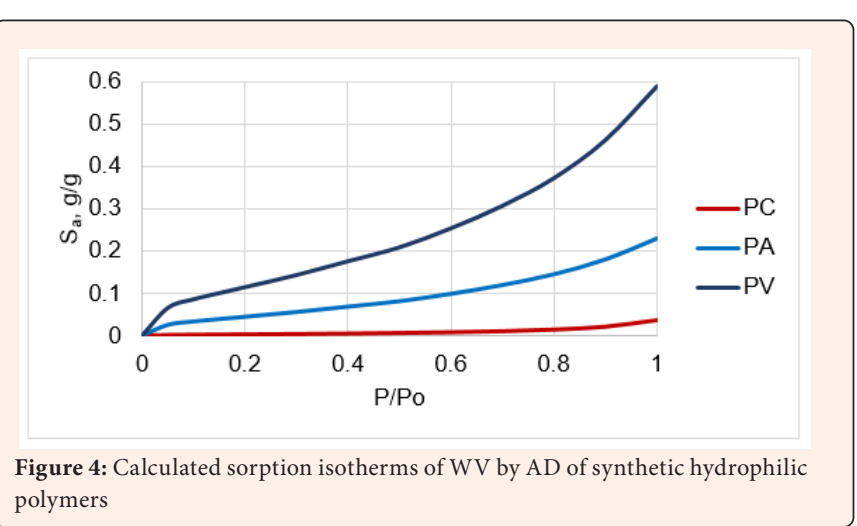

Alternatively, equation (10) can be transformed into equation (11) [25]:

$$
\mathrm{S}_{\mathrm{a}}(\mathrm{g} / \mathrm{g})=\mathrm{S}_{\mathrm{a}, \mathrm{o}}(1-\mathrm{K} \ln \varphi)^{-1}(11)
$$

Where $\mathrm{S}_{\mathrm{a}, \mathrm{o}}=\mathrm{A}_{\mathrm{a}, \mathrm{o}}(\mathrm{MW} / \mathrm{MU})$ is the maximum amount of water molecules absorbed by AD at $\varphi=1$, and $\mathrm{K}$ is the coefficient (Table 4).

Table 4: Parameters of eq. (11)

\begin{tabular}{|l|l|l|l|l|}
\hline Polymer & $\mathbf{K}$ & $\mathbf{S}_{\mathrm{a}, \mathrm{o}}$ & $\mathbf{C}_{\mathrm{p}}$ & $\mathrm{HI}$ \\
\hline C5P (Xylan) & 2.7 & 0.420 & 1.64 & 0.71 \\
\hline C6P (Cellulose and Starch) & 2.7 & 0.506 & 1.95 & 0.86 \\
\hline Chitin (CT) & 2.7 & 0.404 & 1.55 & 0.68 \\
\hline Polyvinyl alcohol (PV) & 2.6 & 0.590 & 2.27 & 1 \\
\hline Polyamide (PA) & 2.6 & 0.230 & 0.88 & 0.39 \\
\hline Polycaprolactone (PC) & 6.8 & 0.037 & 0.07 & 0.06 \\
\hline
\end{tabular}

To estimate the relative hydrophilicity index (HI) of various studied polymers, the following ratio was calculated:

$$
\mathrm{HI}=\mathrm{S}_{\mathrm{o}, \mathrm{a}}(\mathrm{P}) / \mathrm{S}_{\mathrm{o}, \mathrm{a}}(\mathrm{PV})(12)
$$

where $\mathrm{S}_{0}(\mathrm{P})$ and $\mathrm{S}(\mathrm{PV})$ is the maximum sorption value for $\mathrm{AD}$ of the tested polymer $(\mathrm{P})$ and $\mathrm{PV}$, respectively.

Analysis of the hydrophilicity index showed that the most hydrophilic polymer is polyvinyl alcohol and the least hydrophilic polymer is polycaprolactone. This conclusion can be explained by the fact that the hydrophilicity depends on the concentration of polar groups, $\mathrm{C}_{\mathrm{p}}$, which is the highest for PV (Table 4, Figure 5). 


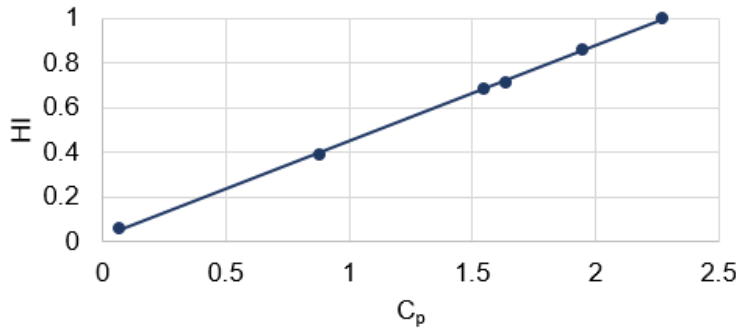

Figure 5: Dependence of hydrophilicity index on the concentration of polar groups

Comparison of calculated and experimental sorption isotherms for samples of hydrophilic polymers

To derive the equation of sorption isotherm for a semicrystalline sample with a degree of amorphicity (Y), it is enough to introduce the Y-value presented in Table 1 into Eq. (11).

$$
\mathrm{S}=\mathrm{Y} \mathrm{S}_{\mathrm{a}, \mathrm{o}}(1-\mathrm{K} \ln \varphi)^{-1}(13)
$$

After that, the calculated isotherms can be plotted and compared with the experimental isotherms (Figures 6 to 9).

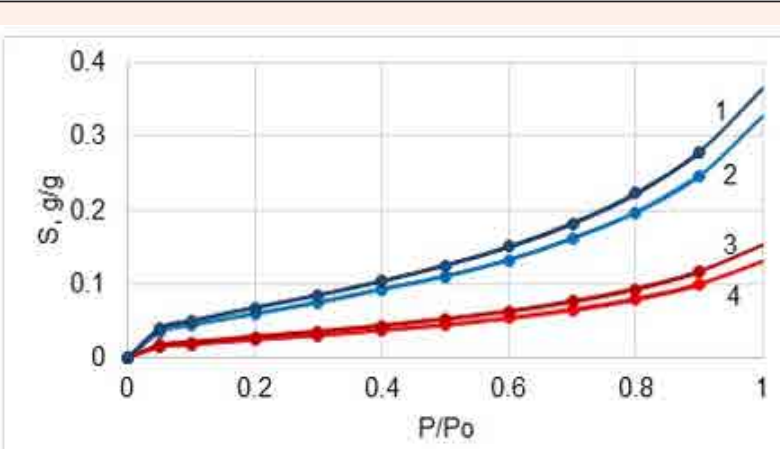

Figure 6: Calculated (lines) and experimental isotherms (points) for semicrystalline samples of natural hydrophilic polymers: ST (1), XL (2), CC (3), and CT (4)

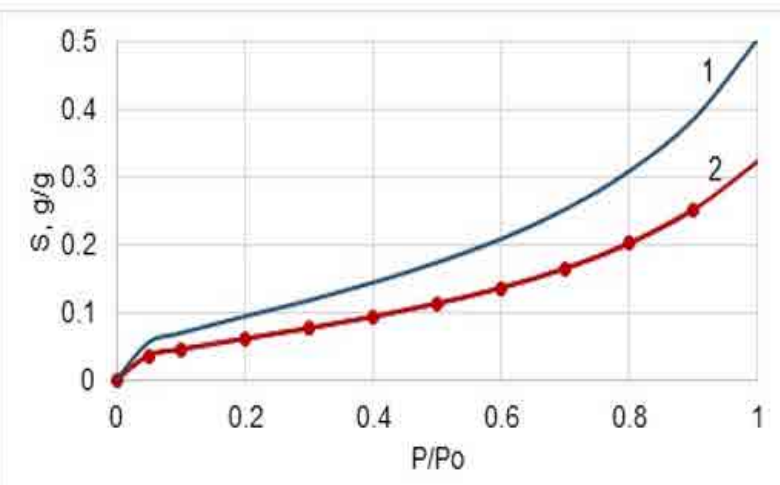

Figure 7: Calculated (lines) and experimental isotherms (points) for AD of C6P (1) and semicrystalline rayon fibers (2)

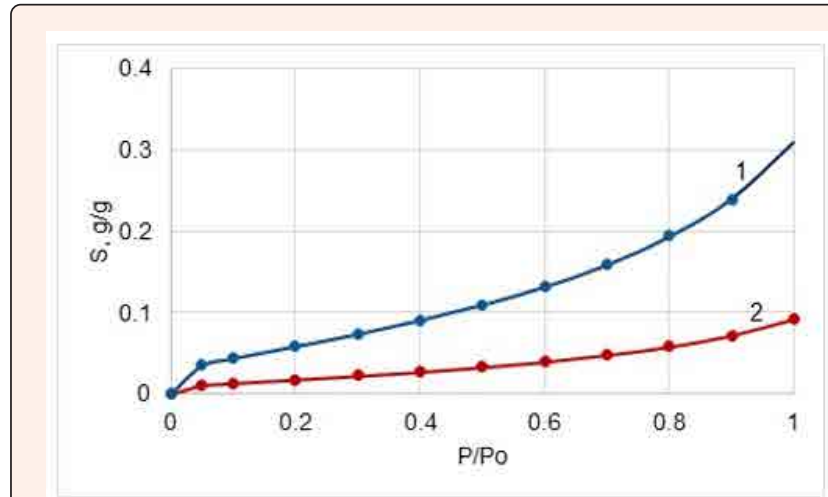

Figure 8: Calculated (lines) and experimental isotherms (points) for semicrystalline samples of synthetic hydrophilic polymers: PV (1) and PA (2)

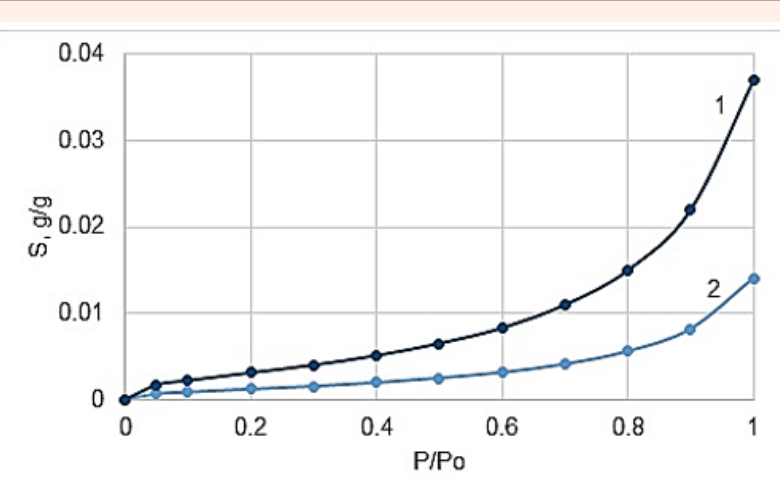

Figure 9: Calculated (lines) and experimental isotherms (points) for AD of PC (1) and semicrystalline synthetic fibers of PC (2).

The obtained results showed that the experimental isotherms are almost identical to the calculated isotherms in a wide $\varphi$-range, from 0 to 0.9 , while for the PA and PC samples these isotherms are identical even in the entire $\varphi$-range, from 0 to 1 . These results prove that the theoretical eq. (13) adequately describes the sorption isotherms for samples of various hydrophilic polymers, both natural and synthetic. For some samples, at high $\varphi$-values above 0.9 , a deviation of the experimental isotherm from the calculated one is observed. It is known that for cellulose and other polysaccharides this phenomenon is caused by capillary condensation $[6,23,25]$. In the case of watersoluble polymers, such as $\mathrm{PV}$, at higher $\varphi>0.9$, the dissolution process of the polymer in absorbed water begins, which also leads to anomalies in the sorption isotherm.

\section{Conclusion}

The known models and equations for the sorption of water vapor by hydrophilic polymers were discussed, such as the Langmuir model of monomolecular surface adsorption, BET, BAG, and other models of multimolecular surface adsorption, as well as models of Henry, Flory-Huggins, and Hailwood-Horrobin of water dissolution in polymers. The mixed models combining various sorption mechanisms were also considered. A critical analysis revealed that these models often do not reflect the sorption mechanism. Furthermore, the calculation of each isotherm needs to be preliminarily found from three to five parameters to achieve the best fit between the calculated and experimental isotherms. Thus, the models are mathematically adapted to the experimental isotherm without proof of the sorption mechanism. In addition, even when sorption occurs according to the same mechanism, various authors use different models and equations. In this study, it was confirmed that the main mechanism of WV sorption by hydrophilic polymers is the volume absorption of water molecules in the amorphous domains of these polymers. Based on the absorption mechanism and the Van Krevelen method of group contributions, a universal equation was proposed: $\mathrm{S}_{\mathrm{a}}(\mathrm{g} / \mathrm{g})=(\mathrm{MW} / \mathrm{MU}) \sum \mathrm{n}_{\mathrm{i}} \mathrm{a}_{\mathrm{o}, \mathrm{i}}\left(1-\mathrm{C}_{\mathrm{i}} \ln \varphi\right)^{-1}$, which makes it possible to adequately describe the sorption isotherms of amorphous hydrophilic polymers 
knowing only the chemical formulas of repeating units these polymers. To calculate the sorption isotherms for semicrystalline samples, it is necessary to use an additional parameter, namely the degree of amorphicity (Y). The adequacy of the derived equation was verified for samples of cellulose and other natural polysaccharides, as well as for samples of synthetic hydrophilic polymers such as polyvinyl alcohol, polyamide- 6 , and polycaprolactone having various Y-values. The verification showed that the experimental isotherms are almost identical to the isotherms calculated by the universal equation.

\section{References}

1. Sionkowska A (2011) Current research on the blends of natural and synthetic polymers as new biomaterials: Review. Progress in Polym Sci 36: 1254-1276.

2. Sazali N, Ibrahim H, Jamaludin AS, Mohamed MA, Salleh WNW, et al. (2020) A short review on polymeric materials concerning degradable polymers. Mater Sci Eng 788: 1-15.

3. Schmidt B (2019) Hydrophilic polymers. Polymers 11: 693-698.

4. Grunin YB, Grunin LY, Schiraya VY, Ivanova MS, Masas DS (2020) Cellulosewater system's state analysis by proton nuclear magnetic resonance and sorption measurements. Biores Bioprocess 7: 1-11.

5. Andrade RD, Lemus R, Pérez C (2011) Models of sorption isotherms for food uses and limitations. Vitae 18: 325-334

6. Papkov SP, Fainberg EZ (1976) Interaction of Cellulose and Cellulosic Materials with Water, Chemistry, Moscow.

7. Timmermann EO (2003) Multilayer sorption parameters: BET or GAB values. Colloid Surface 220: 235-260.

8. Czepirsky L, Komarowska- Czepirska E, Szymonska J (2002) Fitting of different models for water vapor sorption on potato starch granules. Appl Surface Sci 196: 150-153.

9. Brousse MM, Linares RA, Vergara ML, Nieto AB (2017) Adsorption isotherm of dehydrated mashed cassava from different varieties. RECyT 19: 29-37.

10. Blahovec J, Yanniotis S (2008) GAB generalized equation for sorption phenomena. Food Bioprocess Technol 1: 82-90.

11. Roja J, Moren S, Lopez A (2011) Assessment of the water sorption properties of several microcrystalline celluloses. J Pharm Sci Res 3: 1302-1309.
12. Broudin M, Le Saux V, Le Gac PY, Champy C, Robert G, et al. (2015) Moisture sorption in polyamide 6.6: experimental investigation and comparison to four physical-based models. Polymer Testing 171: 87-95.

13. Hill CAS, Norton A, Newman G (2009) The water vapor sorption behavior of natural fibers. J Appl Polym Sci 112: 1524-1537.

14. Park GS (1986) Transport Principles-Solution, Diffusion and Permeation in Polymer Membranes. In: editor names (eds) Bungay PM, Lonsdale HK, de Pinho MN, Synthetic Membranes: Science, Engineering and Applications, NATO ASI Series C: Mathematical and Physical Sciences, vol 181. Springer, UK.

15. Bessadok A, Langevin D, Gouanvé F, Chappey C, Roudesli S, et al. (2009) Study of water sorption on modified Agave fibres. Carbohyd Polym 76: 74-85.

16. Chalykh AE, Bardyshev II, Petrova TF (2021) Free volume and water sorption by cellulose esters. Polymers 13: 2644-2658.

17. Ostrovskii VE, Tsurkova BV (1998) The polyacrylamide-water system: application of differential calorimetry to study the mechanisms of dissolution. Thernrochim Acta 316(2): 111-122.

18. Caulfield DF, Steffes RA (1989) Water-induced recrystallization of cellulose. TAPPI 52: 1361-1367.

19. Paes SS, Sun Sh, MacNaughtan W, Ibbett R, Gangster J, et al. (2010) The glass transition and crystallization of ball milled cellulose. Cellulose 17: 693-709.

20. Parodi E (2017) Structure Properties Relations for Polyamide-6, Univ Press, Netherlands.

21. 21 Prusov AN, Prusova SM, Radugin MV, Zakharov AG (2014) Interrelation between the crystallinity of polysaccharides and water absorption. Ru J Phys Chem 88: 813-818.

22. Ioelovich M (2016) Physico-chemical method for determination of cellulose crystallinity. SITA 18: 35-42.

23. Ioelovich M, Leykin A (2011) Study of sorption properties of cellulose and its derivatives. Bioresources 6: 178-195

24. Van Krevelen DW, Nijenhuis K (2009) Properties of Polymers: Correlations with Chemical Structure, Elsevier, Amsterdam.

25. Ioelovich M (2021) Study of hydrophilic properties of polysaccharides. Organic Polymer Material Research 3:12-23. 